\title{
$\beta$-Glucan ameliorates the effects of several infections
}

Vaclav Vetvicka* and Jana Vetvickova

${ }^{*}$ Correspondence: Vaclav.vetvicka@louisville.edu

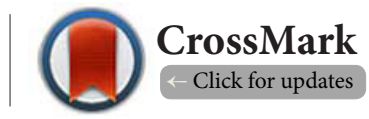

University of Louisville, Department of Pathology, Louisville, KY, USA.

\begin{abstract}
Background: Glucans are known for their effects on anti-infection immunity. However, the individual papers always focused on one glucan, and no attempts were ever made to use one particular glucan in numerous infection.

Methods: In our study, we use yeast-derived glucan \#300, previously shown to ameliorate the effects of two different infections, to evaluate its anti-infection effects on mouse model of Mycobacteria bovis, Aeromonas hydrophila and Escherichia coli infection. Effects of supplementation was evaluated after 14 days of oral suppelentation with glucan.

$\underline{\text { Results: }}$ In case of $E$. coli infection, we found glucan treatment achieved strong improvements in lowering numbers of bacterial in the spleen. Similar effects were found in the number of specific antibodies and survival. Similarly, glucan supplementation caused significant reduction of tissue bacterial load in Aeromonas infection and the spleen of Mycobacterium bovis infected mice.
\end{abstract}

Conclusions: Our results clearly demonstrated that once the glucan significantly improved anti-infection reaction of mice.

Keywords: Glucan, infection, immunity, survival, supplementation

\section{Introduction}

Natural products, useful in treating and/or preventing numerous diseases, have been sought throughout mankind's history. Currently, there are more than 50,000 dietary supplement products marketed just in the United States alone and over $50 \%$ of the American population takes at least one dietary supplement each day. Most of these natural products are plagued with a common problem, i.e., the fact that they often represent a complex mixture of individual ingredients each of which can contribute to their biological activity. Natural (1,3)- $\beta$-D-glucans (glucan thereafter)isolated from yeast, grain and mushrooms are well-established biological response modifiers $[1,2]$ representing highly conserved structural components of cell walls. Glucan's role as a natural immunomodulator has been well documented for over 50 years. Interest in the immunomodulatory properties of polysaccharides was initially raised after experiments showing that a crude yeast cell preparation stimulated macrophages via activation of the complement system [3].

The effects of glucan on anti-infection immunity are among the oldest effects of glucan studied. It has been demonstrated that glucans protect against infection, with both bacteria and protozoa, in several experimental models and was shown to enhance antibiotic efficacy in infections with antibiotic-resistant bacteria. The protective effect of glucans was evidenced in experimental infection with Leishmania major and Leishmaniadonovani, Candida albicans, Toxoplasma gondii, Streptococcus suis, Plasmodium berghei, Staphylococcus aureus, Escherichia coli, Mesocestoides corti, Trypanosoma cruzi and Eimeria vermiformis (for review see [4]). Effects of glucan on parasites are summarized here [5]. Some detailed studies have shown significant synergy of glucan with common antibiotics. Original studies done on guinea pigs demonstrated that simultaneous administration of glucan and antibiotics elevated the ability of animals to resist lethal septic infection by antibiotic-resistant bacteria [6]. In addition to hundreds of reports on glucans stimulating the immune response against many infections, there have been numerous studies, including clinical trials, conducted with glucan and infections in humans. Alpha-Beta Technologies conducted a series of human trials in the 1990s. Using double blind, placebo-controlled trials, these studies showed that patients who received glucan had significantly less infections, a decrease in the use of antibiotics, less complications 
and a shorter stay in the intensive care unit [7]. Subsequent trials including a phase III clinical trial showed that glucan therapy reduced serious postoperative infections by $39 \%$ after high-risk non-colorectal surgery. Another study focused on vulvovaginal candidiasis, which is among the most prevalent vaginal diseases. The experiments showed that glucan induced reactive oxygen production in human neutrophils and release of important cytokines. It strongly indicates that glucan can be an efficient immunomodulator that triggers an increase in the resistance to various microorganisms [8].

\section{Material and Methods \\ Animals}

Female, 8 week old BALB/c mice were purchased from the Jackson Laboratory (Bar Harbor, ME). All animal work was done according to the University of Louisville IACUC protocol. Animals were sacrificed by $\mathrm{CO}_{2}$ asphyxiation. Nine mice/group were used.

\section{Material}

Yeast-derived insoluble Glucan \#300 was purchased from Transfer Point (Columbia, SC). The purity is over $85 \%$. Auramin O was purchased from Sigma (St. Louis, MO, USA).

\section{Experimental groups}

A control group of nine mice was administered PBS. The glucan-supplemented group received $100 \mathrm{mg} /$ mouse of glucan orally for 14 days prior to the experiment.

\section{Infection}

Mice were infected by intragastric application of one dose of Escherichia coli (Sigma, St. Louis, USA) at $5 \times 10^{6} \mathrm{CFU} / \mathrm{ml}$. In another set of experiments, mice were injected iv. withMycobacteria bovis ( $2 \times 10^{5} /$ mouse in $0.1 \mathrm{ml}$ of PBS) [9]. The optimal dilution was determined in preliminary experiments. The challenge was performed by ip. injection of $100 \mathrm{ml}$ of bacterial suspension containing $5 \times 10^{9}$ of bacteria in PBS [10]. Aeromonas hydrophila strain (ATCC07966) was maintained and subcultured in liquid peptone broth three times before experiments. Mice were orally fed with bacterial suspension of $A$. hydrophila ( $0.2 \mathrm{ml}$ containing $2 \times 10^{8} \mathrm{CFU} /$ mouse/week) for 4 weeks. A second group obtained both bacteria and glucan administered same way [11].

\section{Antibodies}

A total Ig level was measured by an anti-mouse Ig-Px antibodies and ELISA assay using plates coated overnight with a standardized suspension of heat-inactivated E. coli at $2 \times 10^{8}$ $\mathrm{CFU} / \mathrm{ml}$ in $\mathrm{pH} 9.0$ carbonate/bicarbonate buffer.

\section{Microscopy}

Levels of M. bovis bacteria were evaluated by fluorescence microscopy. Bacteria were labeled with auramin $\mathrm{O}$ in formaldehydefixed spleen homogenates at various intervals after the challenge.

\section{Antibiotics}

Mice were treated with streptomycin (Sigma) at $5 \mathrm{~g} / \mathrm{l}$ in drinking water for 7 days.

\section{Statistics}

Student's t-test was used to statistically analyze the data. Data at $p<0.05$ were considered significantly different.

\section{Results}

First we focused on effects of glucan supplementation on infection with E. coli. Results shown in Figure 1 showed that glucan treatment achieved similar improvements in lowering numbers of bacterial in the spleen as treatment with antibiotics. When we measured the level of specific antibodies, the glucan supplementation or antibiotic treatment has statistically identical effects (Figure 2). The survival curve demostrated that both glucan and antibodies similarly protected the infected animals, with the antibodies being slightly more active at the
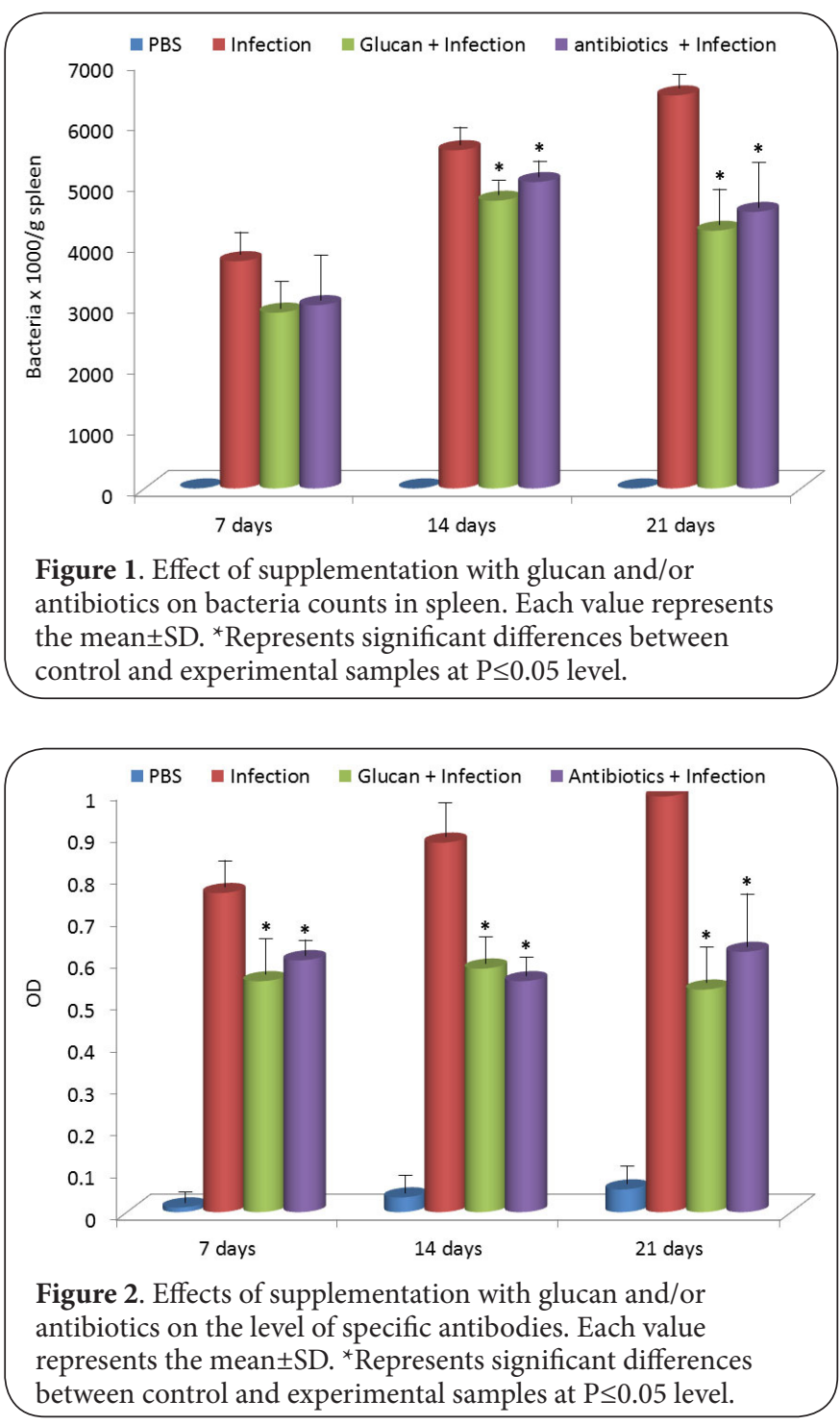
end of the study (Figure 3).

When we tested the effects on Aeromonas infection, glucan was found to strongly reduce the tissue bacterial load (Figure 4). As far as survival is concerned, glucan supplementation improved the survival rate from day for till the end of the study (Figure 5).

Addition of glucan to the diet also improved the bacterial load in the spleen of Mycobacterium bovis infected mice (Figure 6), clearly showing the anti-infectious effects of glucan supplementation.

\section{Discussion}

Glucans are well-established immunomodulators with marked ability to improve the host response to bacterial, viral or parasitic infections. For details about the protective effects of glucan in parasitic infection seerecent review [5]. Lentinan showed prophylactic effects on experimental tuberculosis

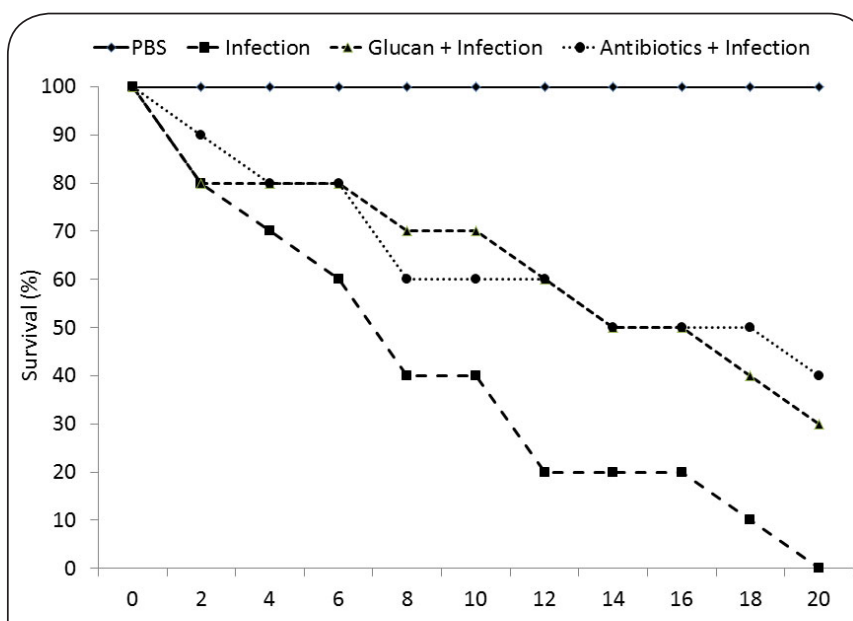

Figure 3. Effects of supplementation with glucan and/or antibiotics on survival rate after $E$. coli infection.

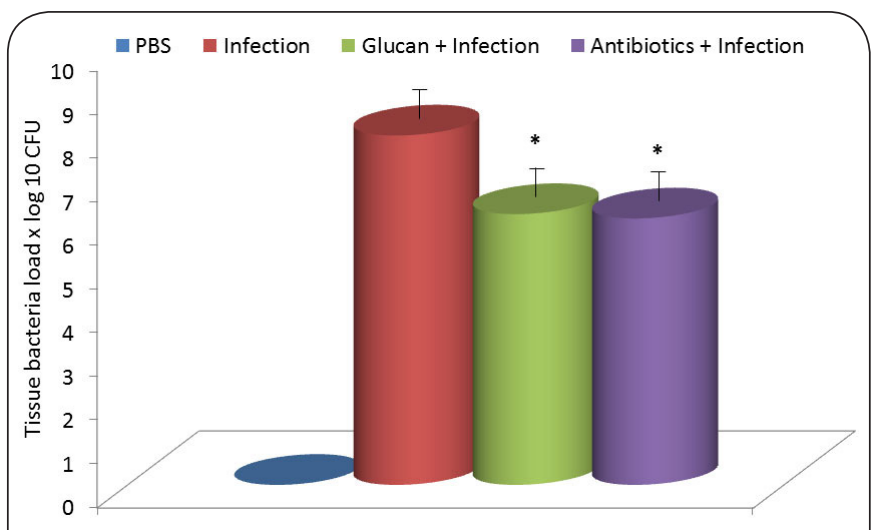

Figure 4. Effects of supplementation with glucan and/or antibiotics on tissue bacterial load in A. hydrophila infection. Each value represents the mean \pm SD. ${ }^{\star}$ Represents significant differences between control and experimental samples at $\mathrm{P} \leq 0.05$ level.

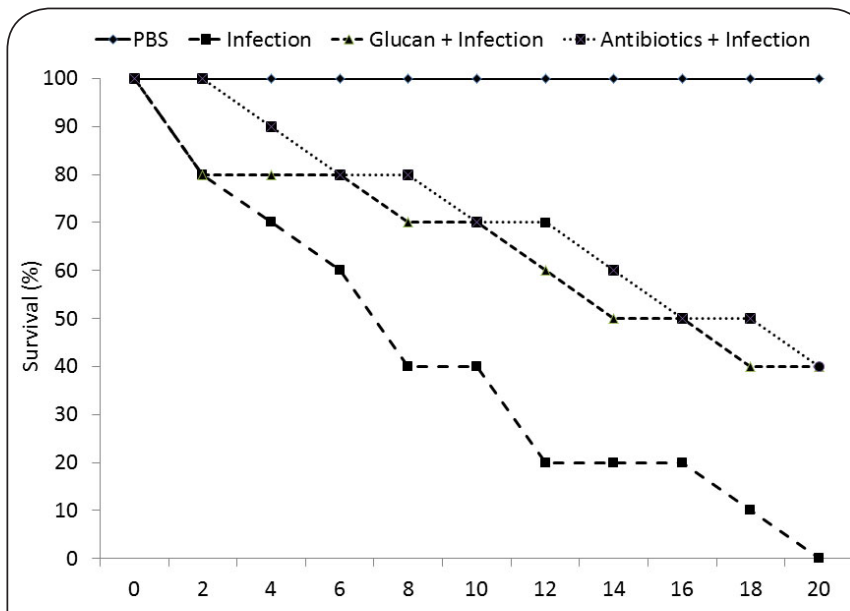

Figure 5. Effects of supplementation with glucan and/or antibiotics on survival rate after A. hydrophila infection.

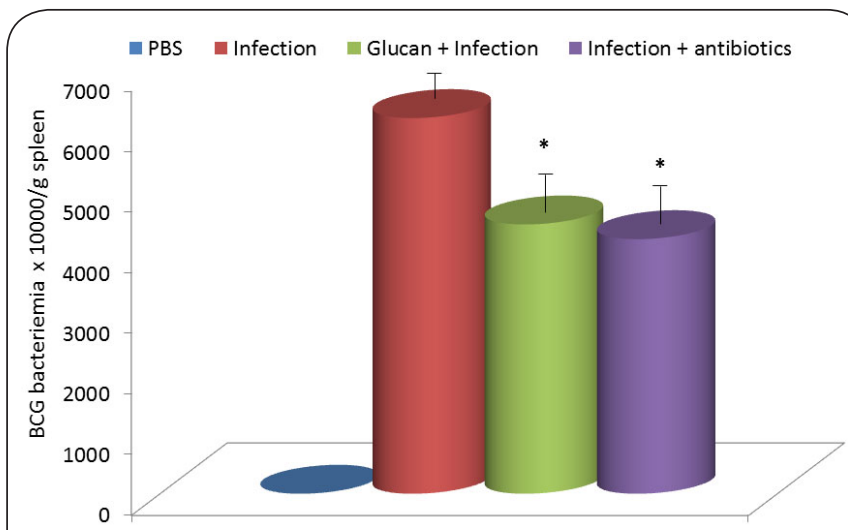

Figure 6. Effects of supplementation with glucan and/or antibiotics on tissue bacterial load in $M$. bovis infection. Each value represents the mean $\pm S D$. ${ }^{*}$ Represents significant differences between control and experimental samples at $\mathrm{P} \leq 0.05$ level.

via improvements in defense reactions [12]. Oat glucan administered either parenterally or intragastrically on mice infected with Eimeria vermiformis increased formation of specific antibodies and reduced fecal oocyst shedding [13], improvement in case $E$. coli infection were found to be mediated via increase release of numerous cytokines including IL-1 [14]. Purified mushroomglucan ameliorates pulmonary sepsis caused by antibiotic-resistant Klebsiella [15], barley glucan showed antibacterial effects in Staphylococcus infection [16].

Yeast-derived glucan stimulation was found not only improve the resistance against bacterial infection, but also work in synergy with antibiotics [17]. Browder et al. studied the stimulation of human macrophages in trauma patients and found that glucan therapy strongly decreased septic morbidity. A multicenter, double blind study found the optimal dosage of yeast glucan in high-risk surgical patients [17]. In addition, these studies demonstrated the safety and efficacy 
Vetvicka et al., Pathology Discovery 2020,

of glucan in surgical patients who underwent major thoracic or abdominal surgery. Since no adverse drug experiences associated with glucan infusion have been found, glucantreated patients had significantly lower levels of infections. The biological effects of glucan on anti-infectious immunity are two-fold: macrophages are activated to produce various substances (such as $\mathrm{H}_{2} \mathrm{O}_{2}$ ), directly killing the bacteria and stimulation of $\mathrm{B}$ lymphocytes to produce more antibodies. Original studies done on guinea pigs demonstrated that simultaneous administration of yeast glucan and antibiotics elevated the ability of animals to resist lethal septic infection by antibiotic-resistant bacteria [6]. At the same time, those results suggested that the use of glucan can help to lower the doses of antibiotics in commercial farming, which is particularly important since there is a strong effort to completely abandon the use of antibiotics in all farmed animals. Positive effectsof lentinan were also found in patients after cardiopulmonary bypass [18]. Using double blind, placebo-controlled trials, additional studies showed thatyeast glucan-supplemented patients had significantly less infections, a decrease in the use of antibiotics, less complications and a shorter stay in the intensive care unit [7]. A different approach was used by Svidzinski group. They focused on vulvovaginal candidiasis, which is among the most prevalent vaginal diseases. The experiments showed that algae-derived glucan induced reactive oxygen production in human neutrophils and release of important cytokines. It strongly indicates that glucan can be an efficient immunomodulator that triggers an increase in the microbicidal response in these health problems [8].

Original studies done on guinea pigs demonstrated that simultaneous administration of yeast glucan and antibiotics elevated the ability of animals to resist lethal septic infection by antibiotic-resistant bacteria [6]. At the same time, those results suggested that the use of glucan can help to lower the doses of antibiotics in commercial farming, which is particularly important since there is a strong effort to completely abandon the use of antibiotics in all farmed animals.

In the current study, we decided to evaluate the antibacterial effects of glucan \#300. This yeast-derived, insoluble glucan has been previously found to suppress cancer development [19], improved stress [20] and fatigue [21], but antibacterial [22] and antiviral effects [23] were tested only rarely.

Using three different models of infection, we evaluated the effects of glucan supplementation. In all three models we found significant improvements in both bacterial counts and survival rates, which is in agreement with the current literature. It is clear that glucan supports the immune system in all types of infection, which suggest the possibility that glucan will be developed for a possible clinical use in treatment of various infections. In our preliminary experiments we already evaluated the effects of this particular glucan on two different models of infection. Using a model of urinary tract infection, we found significant improvements of the amounts of $E$. coli in the bladder after yeast glucan supplementation
[22]. In a model of mouse pneumonia, we found that yeast glucan supplementation lead to significant depression of bacterial counts in BALF [22]. Together with the current study, we conclude that yeast derived, insoluble glucan \#300 has broad action against numerous bacterial infections. The exact mechanisms of the anti-infectious action of glucan are currently under investigation.

\section{Competing interests}

The authors declare that they have no competing interests. Authors' contributions

\begin{tabular}{|l|c|c|}
\hline Authors' contributions & VV & JV \\
\hline Research concept and design & $\checkmark$ & $\checkmark$ \\
\hline Collection and/or assembly of data & $\checkmark$ & $\checkmark$ \\
\hline Data analysis and interpretation & $\checkmark$ & $\checkmark$ \\
\hline Writing the article & $\checkmark$ & -- \\
\hline Critical revision of the article & $\checkmark$ & $\checkmark$ \\
\hline Final approval of article & $\checkmark$ & $\checkmark$ \\
\hline Statistical analysis & -- & $\checkmark$ \\
\hline
\end{tabular}

Publication history

EIC: Markus H. Frank, Harvard Medical School, USA. Received: 08-Aug-2020 Final Revised: 05-Oct-2020 Accepted: 12-Oct-2020 Published: 18-Oct-2020

\section{References}

1. Borchers AT, Stern JS, Hackman RM, Keen CL, Gershwin ME. Mushrooms, tumors, and immunity. Proc SocExpBiol Med. 1999; 221:281-293.

2. Brown GD, Gordon S. Fungal $\beta$-glucans and mammalian immunity. Immunity 2003; 19:311-315.

3. Benacerraf $B$, Sebestyen MM. Effect of bacterial endotoxins on the reticuloendothelial system.Fed Proc. 1957; 16: 860-867.

4. Vetvicka V, Novak M. Biological action of $\boldsymbol{\beta}$-glucan. In V. Vetvicka, M. Novak (Eds.), Biology and Chemistry of Beta Glucan, 2011, Vol. 1, pp. 1018, Bentham Science.

5. Vetvicka V, Fernandez-Botran AR. $\beta$-Glucan and parasites. Helmintologia 2018; 55:177-184.

6. KernodleDS, Gates H, Kaiser AB.Prophylactic anti-infective activity of poly-[1-6]- $\beta$-D-glucopyranosyl-[1-3]- $\beta$-D-glucopyranose glucan in guinea pig model of staphylococcal would infection.Antimicrobial Agents Chemotherap.1998; 42: 545-549.

7. Babineau TJ, Marcello P, Swalis W, Kenler A, Bistrian B, Forse RA. Randomized phase I/II trial of a macrophage-specific immunomodulatory (PGG-glucan) in high-risk surgical patients. Annals Surgery. 1994; 220: 601-609.

8. Bonfim-Mendonca PS, Ratti BA, Godoy JSR, Negri M, Alves de Lima NC, Fiorini A, Hatanaka E, Consolaro MEL, de Oliveira Silva S, Svidzinski TIE. $\beta$-Glucan induces reactive oxygen species production in human neutrophils to improve the killing of Candida albicans and Candida glabrata isolates from vulvovaginal candidiasis. Plos One.2014; 9, e107805, Doi:10.1371/journal.pone.0107805

9. Hetland G, Johnson E, Eide DM, Grinde B, Samuelsen ABC, Wiker GH. Antimicrobial effects of $\beta$-glucans and pectin and of the Agaricusblazeibased mushroom extract, AndoSan. Examples of mouse models for pneumococcal-, fecal bacterial-, and mycobacterial infections. In: Microbial Pathogens and Strategies for Combating Them: Science, Technology and Education, pp. 889-898, 2013.

10. Estrada A, Yun CH, Kessel AV, Li B, Hauta S, Laarveld B. Immunomodulatory activities of oat $\beta$-glucan in vitro and in vivo. Microbiollmmunol.1997; 41:991-998. 
Vetvicka et al., Pathology Discovery 2020,

http://www.hoajonline.com/journals/pdf/2052-7896-8-2.pdf

11. Abuelsaad ASA, Mohamed I, Allam G, Al-Solumani AA. Antimicrobial and immunomodulating activities of hesperidin and ellagic acid against diarrheic Aeromonashydrophila in a murine model.Life Sciences.2013; 91:714-722.

12. Markova N, Kussovski V, Drandarska I, Nikolaeva S, Georgieva N, Radoucheva T. Protective activity of lentinan in experimental tuberculosis. Int/mmunopharmacol. 2003; 3:1557-1562.

13. Yun CH, Estrada A, Van Kessel A, Gajadhar A, Redmond M, Laarveld $B$. Immunomodulatory effects of oat $\beta$-glucan administered intragastrically or parenterally on mice infected with Eimeria vermiformis.Microbiollmmunol.1998; 42:457-465.

14. Rasmussen LT, Seljelid R. Novel immunomodulators with pronounced in vivo effects caused by stimulation of cytokine release.J Cell Biochem.1991; 46:60-68.

15. Masterson CH, Murphy EJ, Gonzales H, Major I, McCarthy SD, O’Toole D Laffrey JG, Rowan NJ. Purified beta-glucans from the Shiitake mushroom ameliorates antibiotic-resistant Klebsiella pneumoniae-induced pulmonary sepsis.Lett App/Microbiol.2020, doi: 10.1111/lam.13358

16. Song J, Chen H, Wei Y, Liu J. Synthesis of carboxymethylated $\beta$-glucan from naked barley bran and its antibacterial activity and mechanism against Staphylococcus aureus. Carbohydr Pol. 2020; 242, doi:10.1016/j. carbpol.2020.116418.

17. Browder W, Williams D, Sherwood E, McNamee R, Jones E, DiLuzio N. Synergistic effect of nonspecific immunostimulation and antibiotics in experimental peritonitis.Surgery 1987; 102:206-214.

18. Hamano K, Gohra H, Katoh T, Fujimora Y, Zempo N, Esato K.The preoperative administration of lentinan ameliorated the impairment of natural killer activity after cardiopulmonary bypass. Int J Immunopharm.1999; 21: 531-540,PMID:10458542

19. Yan J, Vetvicka V, Xia Y, CoxonA, Carroll MC, MayadasTN, Ross GD. $\beta$-Glucan, a "specific" biologic response modifier that uses antibodies to target tumors for cytotoxic recognition by leukocyte complement receptor type 3 (CD11b/CD18).J Immunol.1999; 163: 3045-3052

20. Vetvicka V, Vancikova Z. Anti-stress action of several orally-given $\beta$-glucans.Biomed Pap.2010; 154:235-238.

21. Richter J, Kral V, Stiborova I, Rajnohova L, Vetvicka V. Anti-inflammatory effects of b-glucan in cancer related fatigue.J Nutr Health Sci. 2015; 2, 10.15744/2393-9060.2.304

22. Vetvicka V, Vetvickova J. Anti-infectious and anti-tumor activities of $\beta$-glucan.Anticancer Res. 2020; 40:3139-3145.

23. Vetvicka V, Vetvickova J. Glucan supplementation enhances the immune response against an influenza challenge in mice.Ann Transl Med. 2015; 3, doi:10.3978/j.issn.2305-5839.2-15.01.08

\section{Citation:}

Vetvicka $V$ and Vetvickova J. $\boldsymbol{\beta}$-Glucan ameliorates the effects of several infections. Pathol Discov. 2020; 8:2.

http://dx.doi.org/10.7243/2052-7896-8-2 